\title{
A Senior Design Project in Automated Solar Heating System for Learning Green Energy Manufacturing
}

\section{Dr. Richard Y. Chiou, Drexel University}

Dr. Richard Chiou is Associate Professor within the Engineering Technology Department at Drexel University, Philadelphia, USA. He received his Ph.D. degree in the G.W. Woodruff School of Mechanical Engineering at Georgia Institute of Technology. His educational background is in manufacturing with an emphasis on mechatronics. In addition to his many years of industrial experience, he has taught many different engineering and technology courses at undergraduate and graduate levels. His tremendous research experience in manufacturing includes environmentally conscious manufacturing, Internet based robotics, and Web based quality. In the past years, he has been involved in sustainable manufacturing for maximizing energy and material recovery while minimizing environmental impact.

\section{Dr. Irina Nicoleta Ciobanescu Husanu, Drexel University}

Irina Ciobanescu Husanu, Ph. D. is Assistant Clinical Professor with Drexel University, Engineering Technology program. Her area of expertise is in thermo-fluid sciences with applications in microcombustion, fuel cells, green fuels and plasma assisted combustion. She has prior industrial experience in aerospace engineering that encompasses both theoretical analysis and experimental investigations such as designing and testing of propulsion systems including design and development of pilot testing facility, mechanical instrumentation, and industrial applications of aircraft engines. Also, in the past 10 years she gained experience in teaching ME and ET courses in both quality control and quality assurance areas as well as in thermal-fluid, energy conversion and mechanical areas from various levels of instruction and addressed to a broad spectrum of students, from freshmen to seniors, from high school graduates to adult learners. She also has extended experience in curriculum development. Dr Husanu developed laboratory activities for Measurement and Instrumentation course as well as for quality control undergraduate and graduate courses in ET Masters program. Also, she introduced the first experiential activity for Applied Mechanics courses. She is coordinator and advisor for capstone projects for Engineering Technology.

\section{Prof. Tzu-Liang Bill Tseng, University of Texas - El Paso}

Dr. Tseng is a Professor and Chair of Industrial, Manufacturing and Systems Engineering at UTEP. His research focuses on the computational intelligence, data mining, bio- informatics and advanced manufacturing. Dr. Tseng published in many refereed journals such as IEEE Transactions, IIE Transaction, Journal of Manufacturing Systems and others. He has been serving as a principle investigator of many research projects, funded by NSF, NASA, DoEd, KSEF and LMC. He is currently serving as an editor of Journal of Computer Standards \& Interfaces. 


\title{
A Senior Design Project in Automated Solar Heating System for Learning Green Energy Manufacturing
}

\begin{abstract}
The paper presents a senior design project that engages in educational activities to enhance learning in green energy manufacturing, including construction of heat exchanging solar collector system and implementation in the efficient heating of a greenhouse. The goal of the senior design project was to engage students in real-world learning experiences for the design of a greenhouse module integrated with renewable energy as an initial stepping stone for the future construction of manufacturing plants in industry. The renewable energy integrator component in the project seeks to explore the technology of renewable and eco-friendly sources of electricity on a large scale. This design system is comprised of an evacuated tube and a flat panel solar collector both attached to a hot water tank heat exchanger for maximum efficiency. The students incorporated the green energy manufacturing concepts for the design of the control system to actively monitor soil temperatures with the use of a thermocouple sensor all the while maintaining ideal greenhouse conditions by pumping heated fluid through coils underneath the soil surface. The student learning outcome of this project was the successful incorporation of the solar collectors as the exclusive energy input required to heat the greenhouse system in order to decrease food manufacturing costs, expand the profitability of fruit and vegetable harvests, and decrease the environmental impact of greenhouse heating. For the sake of achieving the student learning outcomes, experiments were conducted, including sensor monitoring and process control. A concluding section discusses the student learning experiences during this project.
\end{abstract}

\section{Introduction}

This paper discusses an educational effort that incorporates green energy manufacturing concept for an automated solar heating system in a senior design project at Drexel University [Said, et al, 2015]. A critical component of a national "green industries/green/energy jobs” effort is to motivate student communities and workforce to become proficient in STEM and associated manufacturing fields and trades, thus ensuring a $21^{\text {st }}$-century workforce. This senior design project engages students in the implementation of an innovative method for improving design and measuring energy efficiency using statistical process control. Through this project, students learn how to provide a design method for evaluating the characteristics of green energy manufacturing. This student senior design project was in collaboration with Higginbothom Farm in New Jersey, which is s a commercial farm that supplies restaurants, farmer's markets, and grain for Perdue chicken feed. There has been an increasing demand for delivering its safely planted products with a greenhouse in different seasons. The students incorporated real-world experience with innovative green energy design for the use of hybrid solar collectors, as well as improving energy efficiency.

The main objective of senior design courses in the engineering technology curricula is to bridge the gap between academic theory and real-world practice. Accordingly, the proposed senior projects should include elements of both credible analysis and experimental proofing as mentioned in ABET criteria. The primary intent of this effort is to foster learning of class concepts and to impact the breadth of student learning (in terms of ABET outcomes "(c) an ability to design a system, component, or process to meet desired needs within realistic constraints such as economic, 
environmental, social, political, ethical, health and safety, manufacturability, and sustainability" and (h) "the broad education necessary to understand the impact of engineering solutions in a global, economic, environmental, and societal context"). The senior design project can serve as an excellent culminating experience in the program of study when it focuses on research and design projects that have practical value to consumers or to industry. For the Engineering Technology (ET) Department at Drexel University, the senior design course is a year-long educational journey (three quarters) that takes an idea generated by a student or an industrial sponsor and culminates in a product or project. This course is an excellent capstone experience, which requires both teamwork and individual skills in solving a modern industrial problem. Senior design projects in fall, winter, and spring quarters bring the students, faculty, and industrial partners together to see the student's results and to give them the additional experience of public presentation of their work.

The purpose of this paper is to describe a capstone senior design project involved in the environmentally conscious manufacturing. The experience to improve industrial working environment and process costs in the project is discussed. The senior design project course is a 3term core course usually taken by the students during their terminal year in the ET Department at Drexel University. The design involves an educational effort that incorporates environmental consciousness in the senior design project. Several design approaches are pursued as part of the project for green energy manufacturing. The paper discusses the steps taken and apparatus used for performing design, assembly, and temperature control measurements of greenhouse. For the sake of comparisons for greenhouse design, experiments were conducted, including temperature measurement, solar irradiance analysis, and solar system efficiency. A concluding section discusses the experiences from this project.

\section{Background and Problem Statement}

Efficient and environmentally friendly greenhouse heating solutions have immediate applications in commercial farming. In this modern age, there is a high demand for green and organic agricultural. Greenhouses function extremely well during daytime hours in all climates. In fact, they often have to be vented or shielded during the peak daytime hours to prevent overheating the plants. However, the material used to allow as much light as possible into a greenhouse offers little, if any, insulation. Temperatures plummet drastically when the sun begins to set. Currently farmers and gardeners rely on electric, oil, and propane heaters to maintain temperatures within the greenhouse overnight, or more importantly within the soil or growing media.

During the initial phase of this project, the senior design project team visited the Higginbothom Farm in Marlton, NJ to consult with greenhouse farming experts. Higginbothom Farm is a commercial farm that supplies restaurants, farmer's markets, and grain for Perdue Chicken feed. The Higginbothoms indicated that they currently use oil and propane to heat their greenhouses. They informed the team that soil temperature is most important for sustained or improved growth and overall plant health. Ideally, soil temperature should be kept above $60^{\circ} \mathrm{F}$. In reality, air temperature is generally not as important. For this reason, the best way to maintain proper growth would be to heat the soil itself. This is currently done using heaters within or beneath the soil. The Higginbothom Farm's greenhouses are used during the fall, winter, and spring. Green leafy vegetables such as lettuce, kale, collard greens, and spinach are seeded in the fall and grown entirely inside the greenhouses over the winter months. In February, tomatoes, cucumber and zucchini are planted in the greenhouses. Tomatoes are the Higginbothom's most profitable harvest. 
They are effectively able to add six extra weeks to the tomato-growing season by using their greenhouses.

Many other fruits and vegetables can be grown in greenhouses. The limiting factor is the cost and inefficiency of heating a greenhouse using electric, gas, or oil. When the team asked Craig and Shannon what type of fruits and vegetables they would like to grow if they had a free fuel source such as solar power, they indicated that they would be able to grow tropical fruits such as mangos, papayas, pineapples and citrus fruits such lemons and limes. They also indicated that humidity is often a huge factor in fruit and vegetable growth. They gave an example of avocado growth. Farmers are currently unable to grow avocados in the northern United States because it is prohibitively expensive to maintain both temperature and high humidity in a greenhouse. The availability of solar hot water heating would make it possible to efficiently maintain both conditions at lower costs [Craig \& Shannon, 2014].

\section{Design Process}

An unnatural weather change is a standout amongst the most predominant ecological issues mankind will need to face in the 21st century. Technology is deeply incorporated into the society. It is part of many people's daily lives, and the majority depends on it to progress. However, when discussing innovation, a clear consensus is drawn; new designs bring both positive and negative aspects to the table. It is up to the engineers to compare and outweigh the negative facets with the overall productivity of the new design. With technology, a moral outlook becomes a required piece of the puzzle that must be fully satisfied to turn the end result into true innovation.

The environment is unfortunately taken for granted, and it appears the more the team develops as individuals, the more the team end up harming it. That being said, the team has better alternatives to continue progressing forward. Renewable energy is an incredible solution to help secure the surroundings and ultimately humanity as a whole. As of late, solar collectors have become a popular solution for supplanting non-renewable assets. Numerous homes have incorporated photovoltaic solar panel arrays to supply their homes with supplemental energy. While a viable solution, these homes are usually still connected to the power grid as a reinforcement vitality source. Solar energy technology has boundless potential with an endless scope of use. One significant application is solar thermal energy.

Solar thermal energy is a form of "free” energy acquired by harnessing the sun's heat to generate thermal power for utilization in industrial, residential and commercial segments. This is carried out principally through the utilization of evacuated tube solar collectors and the less expensive alternative, flat panel solar collectors. Evacuated tube solar collectors capture energy in a vacuum sealed glass tube quickly heating a special, non-toxic, heat-transfer fluid in the copper heat pipe. The heated fluid ascends to the highest point of the channel where it warms the water (or antifreeze) that is constantly circulated through the copper manifold in the insulated aluminum header. As the heat transfer fluid cools, it falls to the bottom of the heat pipe to be reheated. This cyclical process repeats over and over, continually heating the water or fluid passing by it. Interestingly, these types of collectors can extract the heat out of air on a foggy or unclear day and therefore do not require direct sunlight. The performance is actually better when the sun is not at an optimum angle; such as when it is early in the morning or in the late afternoon. 
On the other hand, flat panel solar collectors have been on the market and in use since the early 1900's. These panels consist of the most time tested and well-known technologies. Each panel contains an absorber plate, which is generally a dark painted metal such as copper for maximum heat absorption. This is then attached to copper pipes where water or a heat transfer liquid flows through. The final design is encased in a metal frame, surrounded by thick insulation to help preserve the collected heat. Additionally, the panels are protected by a sheet of glass or glazing, which also provides an insulating air space. One downside of this panel, however, is that it needs to be periodically heated by the heat transfer fluid in order to prevent it from internally freezing during the winter season [Mehalic, 2009].

The system that the team improved upon contained both flat panel and evacuated tube solar collectors connected to a heat exchanging water heater tank. The system was built by a previous design group; however, it was not fully functioning [Solimon, Adams, \& Reidl, 2013]. Recently, photovoltaic panels have become very popular due to lower upfront costs and easier installations, however for heating purposes these panels are not the best choice. Using photovoltaic solar panels to convert solar energy to electrical energy and then finally to thermal heat energy introduces many points of inefficiency. Solar thermal power is more effective at producing heat by essentially capturing the sun's radiant energy and focusing it. One big advantage that solar thermal technology has over direct photovoltaic resistant heating is that it can store this energy depending upon the specific heat of the fluid transfer and containment process. The team aimed to get these two solar collectors to function correctly by installing thermocouple sensors in the pipes so that data can be actively collected to determine which collector is working most efficiency at any time and condition. This collection of data is fed into the control system of the design to engage the panel that is determined to be the most productive at exchanging heat. The green-energy solar collectors were set up and made fully functional.

\section{Energy Efficiency Design Methodology}

Figure 1 shows a graph of both panels' efficiency percentage versus the difference of inlet and ambient temperatures. The most productive operation of a collector is when the temperature of the inlet liquid (Ti) is the same as the surrounding temperature (Ta). Flat panel collectors are usually are $75 \%$ effective when Ti equals Ta, whereas evacuated tubes have a proficiency of around 50\%. Collectors tend to operate $30^{\circ} \mathrm{F}$ to $80^{\circ} \mathrm{F}$ above surrounding temperatures to deliver end-use temperatures from $100^{\circ} \mathrm{F}$ to $130^{\circ} \mathrm{F}$. Efficiency is poor when the inlet temperatures have risen. This causes the heat exchange from the absorber to the encompassing air more likely to occur and as a result, heat will not be transferred to the fluid in the collector [Mehalic, 2009]. Due to the rounded design of evacuated tubes, solar thermal energy can be absorbed evenly all day long ("Flat Panel Vs. Tube”, 2010). Temperatures of evacuated tubes can reach up to $250{ }^{\circ} \mathrm{F}$, and due to superior insulation, the losses in efficiency curves for evacuated tubes are low. As the difference between inlet and ambient temperatures (Ti-Ta) increases, the curve becomes less steep. Flat panels are more productive when Ti equals Ta, however as $\mathbf{T i}$ continues to rise, evacuated tubes are more efficient than their flat-plate counterparts [Mehalic, 2009]. 


\section{Collector Efficiency}

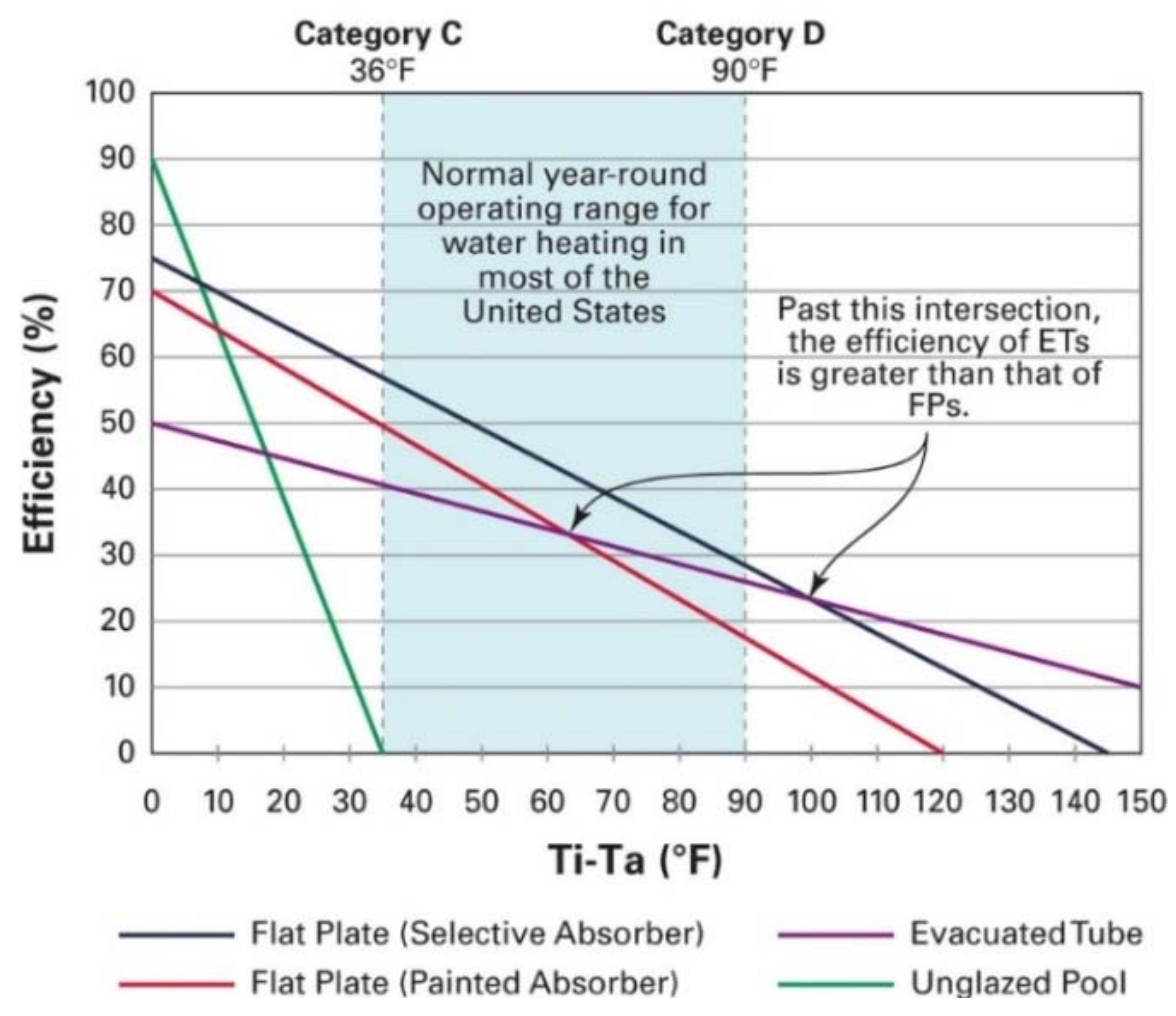

Figure 1: Collector efficiency graph [Mehalic, 2009]

Evacuated tubes also perform much better under cloudy and windy conditions, again, a result of the improved insulation retaining more heat in the collector. For some geographical locations, like Chicago and a majority of the east coast, snow is a problem. By combining two types of solar collectors, evacuated tubes and flat panels, maximum efficiency can be achieved. In evacuated tube's, any light passing through the snow will intersect the effective insulation which in return prevents the heated absorber from warming up the surrounding glass. This is when the flat panel collectors will come into play. Light passing through the snow or frost will not be blocked and will therefore heat the absorber plates. Some of this heat radiates and warms the surrounding glass, which will melt the snow accumulated on top, allowing it to slide off [Williams, 2010]. Combining both panels can be very successful due to dissimilar efficiencies at different temperatures and weather conditions. They both have their advantages and disadvantages and the novelty of consolidating these two systems will result in a single complimenting system for a better overall renewable energy source. It is a new approach to self-sustainment, which will cover a wider range of ambient conditions. With the backgrounds as electrical and mechanical engineers, the integration of the two separate projects has been successfully achieved. The electrical / programming aspect relating to the temperature sensors was accommodated by the team's electrical experience. Furthermore, the mechanical background allowed us to realize the heat transfer and to design the copper tubing assembly. 


\section{Development and Testing of Prototype}

A new base frame (Figure 2 (a)) was designed to mount and transport the system. The base frame was fabricated out of pressure treated wood for weather resistance. The team determined that a Tshaped frame would be a more suitable design to accommodate all of the required components. With this shape the solar panels could be mounted in the front portion of the base frame and the water tank could be mounted behind the solar panels. This resulted in shorter pipe runs between the solar panels as well as shorter wire runs from the electronics to the components. The team was paying special attention to the length of the pipe runs to minimize heat losses. The new base frame shape also allowed us an area to build a cabinet type enclosure for the tank and an elevated mounting surface above the cabinet. Casters were installed beneath the base frame to facilitate transportability.

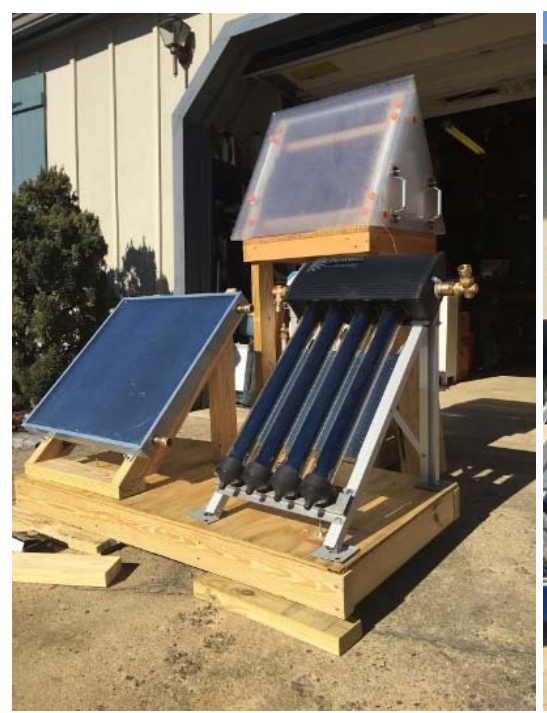

(a)

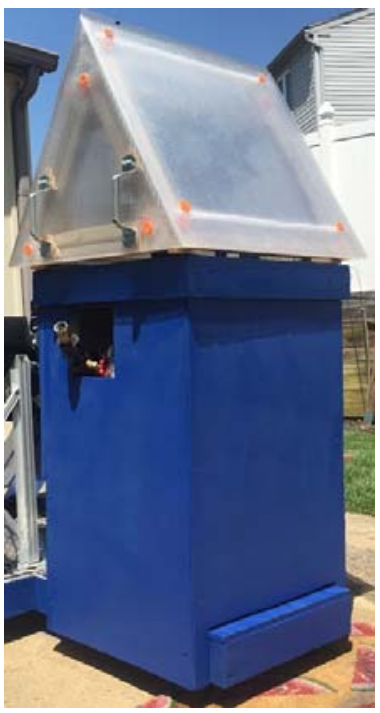

(b)

Figure 2: (a) T-shaped base frame and cabinet and (b) Greenhouse mount

Figure 2(a) also depicts the design of the greenhouse integrated with the solar collectors' circuit. Ventilation holes were cut into the floor of the house holding the flower pot. The legs of the house were extended so that it could sit above the storage tank. The hot water tubes enter the house from below and into the flower pot. The tubes run into a coil placed in the soil of the flower pot and out the other side. The water tube exits the greenhouse through the opposite side of the flower pot. A thermocouple sensor is placed directly inside the pot to determine the soil temperature. The greenhouse is fully enclosed, to keep heat from escaping the system. The previous group designed this house to be a suitable size for demonstration purposes and the ease of transportation. The dimensional parameters of the house are two feet in length by two feet in width. The overall design of the house includes a slanted roof to prevent any snow accumulation and minimal surface area to reduce heat loss issues that other designs are plagued with.

The body of the house consists of non-toxic pressure treated wood so it can withstand various outdoor conditions. The canopy is made up of a polycarbonate material that is removable for the 
ease of transportation and maintenance / replacements if needed. Two layers of $8 \mathrm{~mm}$ twin-wall paneling are used to completely encase the house. The team designed an enclosed and insulated cabinet base for the greenhouse (Figure 2(b)) out of pressure treated lumber. In addition, this cabinet along with base frame unit was painted with a weatherproof epoxy to maintain maximum weather resistance all year long. The cabinet serves the purpose of enclosing the water tank as well as some of the electrical components for weather protection.

\section{Piping System Design with Hybrid Solar collectors}

In a farm environment, space and land are a crucial aspect of how profitable a particular agricultural entitiy may be. As stated before, a more ideal location for the the storage tank (Figure 3 ) would be behind and in between the solar collectors. This decreases the overall surface area of the system for a more efficient and economical design. Another benefit relates primiarly to the new tubing and fitting orientation. In the new design, the length of the tubes is drastically reduced in order to prevent any unnecessary heat and efficiency losses. Additionally, the tubes are insulated to consolidate the heat within the system.

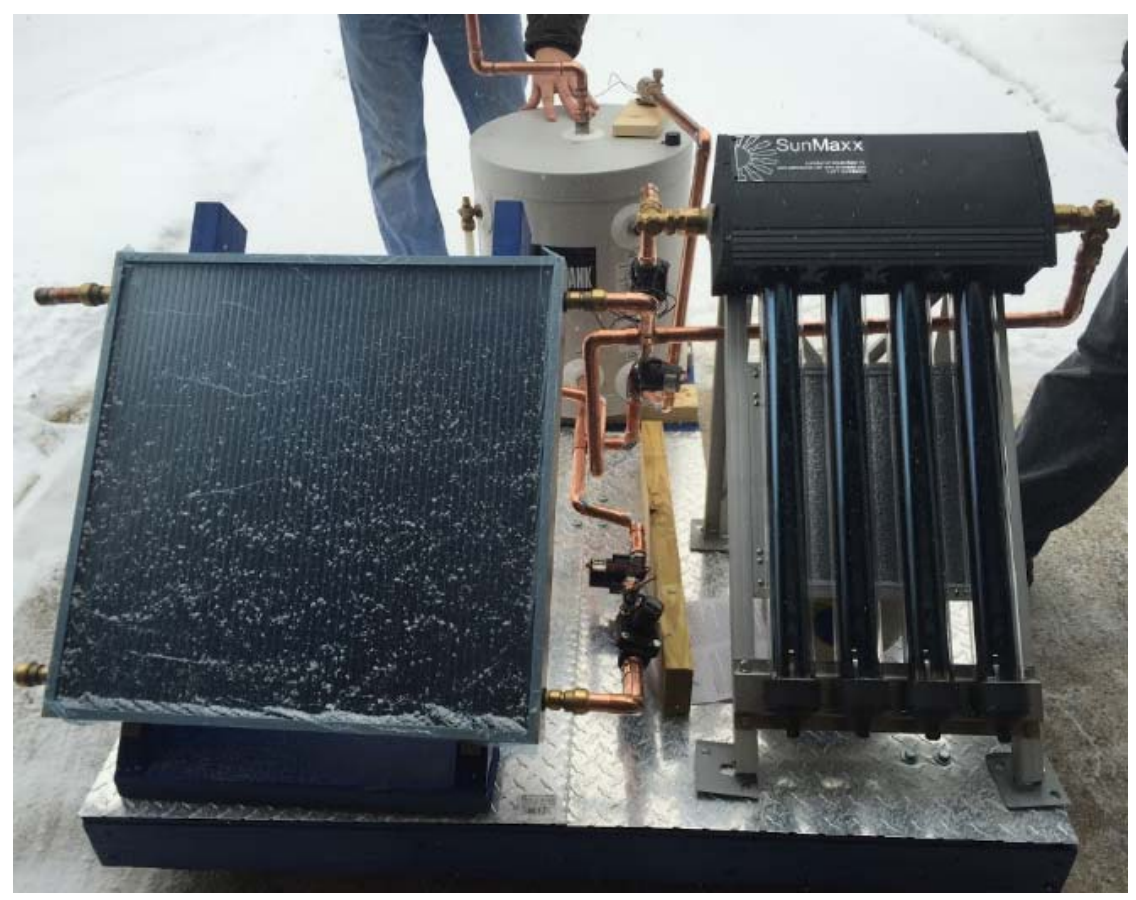

Figure 3: Design with hybrid solar collectors

Rigid copper piping with sweat type connections were chosen for use within this system. By sweating the pipes, a permanent connection is essentially created when the non-lead based solder fuses with the copper pipes. The pipe selection for this application was $3 / 4$ " nominal size, Type L, which is appropriate for residential and commercial supply and pressure applications. Copper piping was chosen specifically because it holds up to high water temperatures, has a huge variety of fitting types, and it is readily available. The wide variety of readily available fitting sizes allowed us to easily mate up or adapt to the various different fitting configurations that the pumps, valves, 
solar collectors, and the water tank/heat exchanger. In Figure 4, the new piping design layout is clearly shown. Another advantage was the availability of insulation. Properly sized and weather resistant insulation for standard copper pipe sizes is available at any local hardware store. It is very important that the team minimize heat losses along the piping system for the program to operate most effectively. The team also added an overflow/over-pressurization tank to the closed loop system. The team needed to protect the system when the water temperatures increased in the piping. Finally fill and drain ports were added to allow for easy transportation and maintenance.

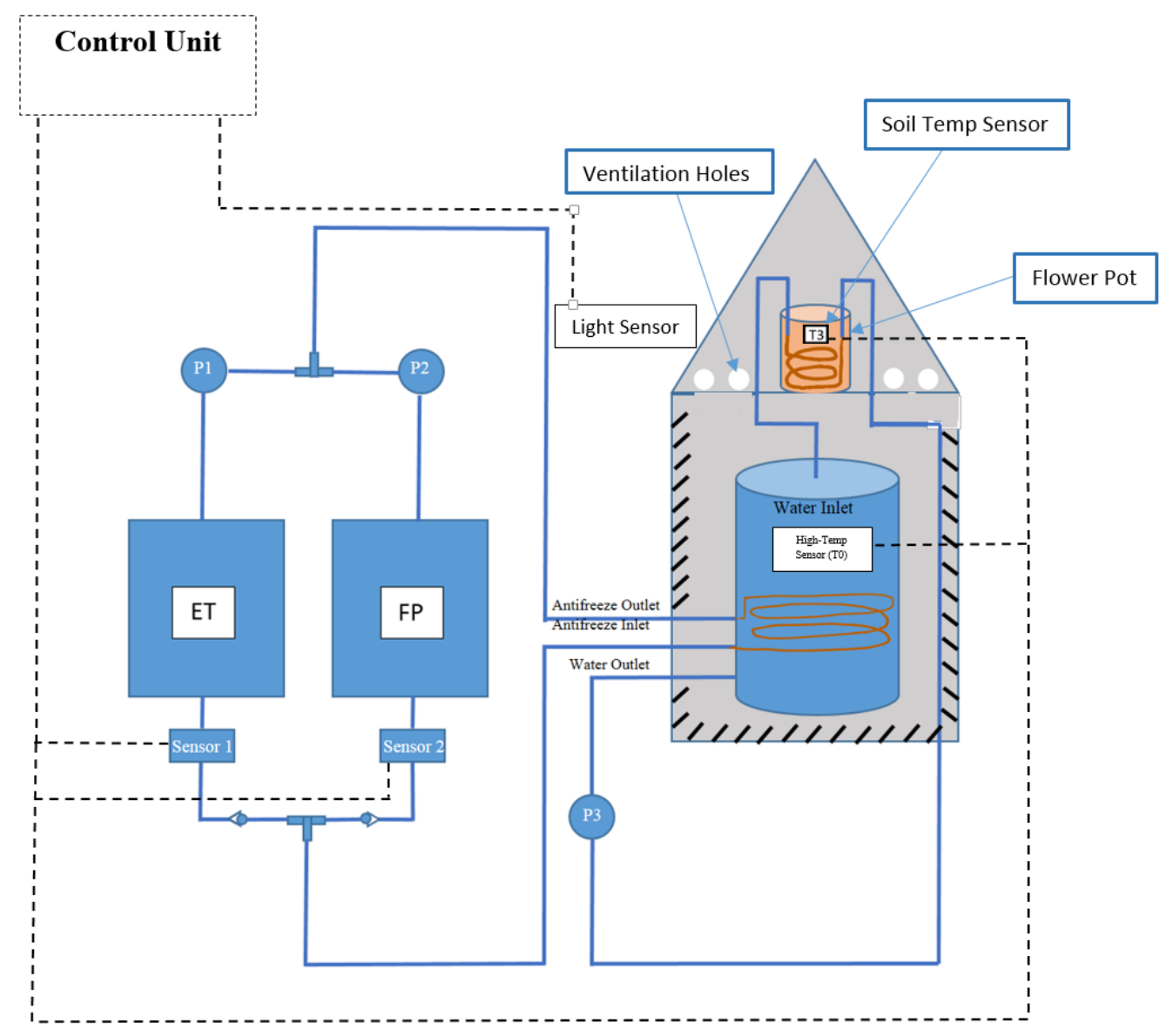

Figure 4: Process flow diagram

\section{Experimental Results}

In Figure 5, a graphical format of the actual experimental data collected on May $8^{\text {th }}$, 2015 was plotted. The orange line indicates the flat plate solar collector temperatures, the blue line indicates the evacuated tube solar collector temperatures, the green line represents the soil temperature, and finally the yellow line indicates the ambient air temperature for that particular day and time. As you can see, the flat plate showed higher temperature throughout the very sunny and hot day, which in turn told the program to run the fluid through that particular collector. At the end of the day as the sun began to fall and some clouds rolled in, the evacuated tube took the reins and the flat plate proved inferior in these conditions. It is very clear to see how effective these panels are at any given time as the temperatures within the system are, on average, twice the value of the ambient 
air. The soil temperatures do not reflect any influence by the system as the temperature never dropped below $60^{\circ} \mathrm{F}$ on this Spring Day. The few dips in temperature were purely for testing purposes to see if the unit was functioning as designed. These data points have allowed us to conclusively evaluate the overall collector system efficiencies in the following graph in Figure 6.

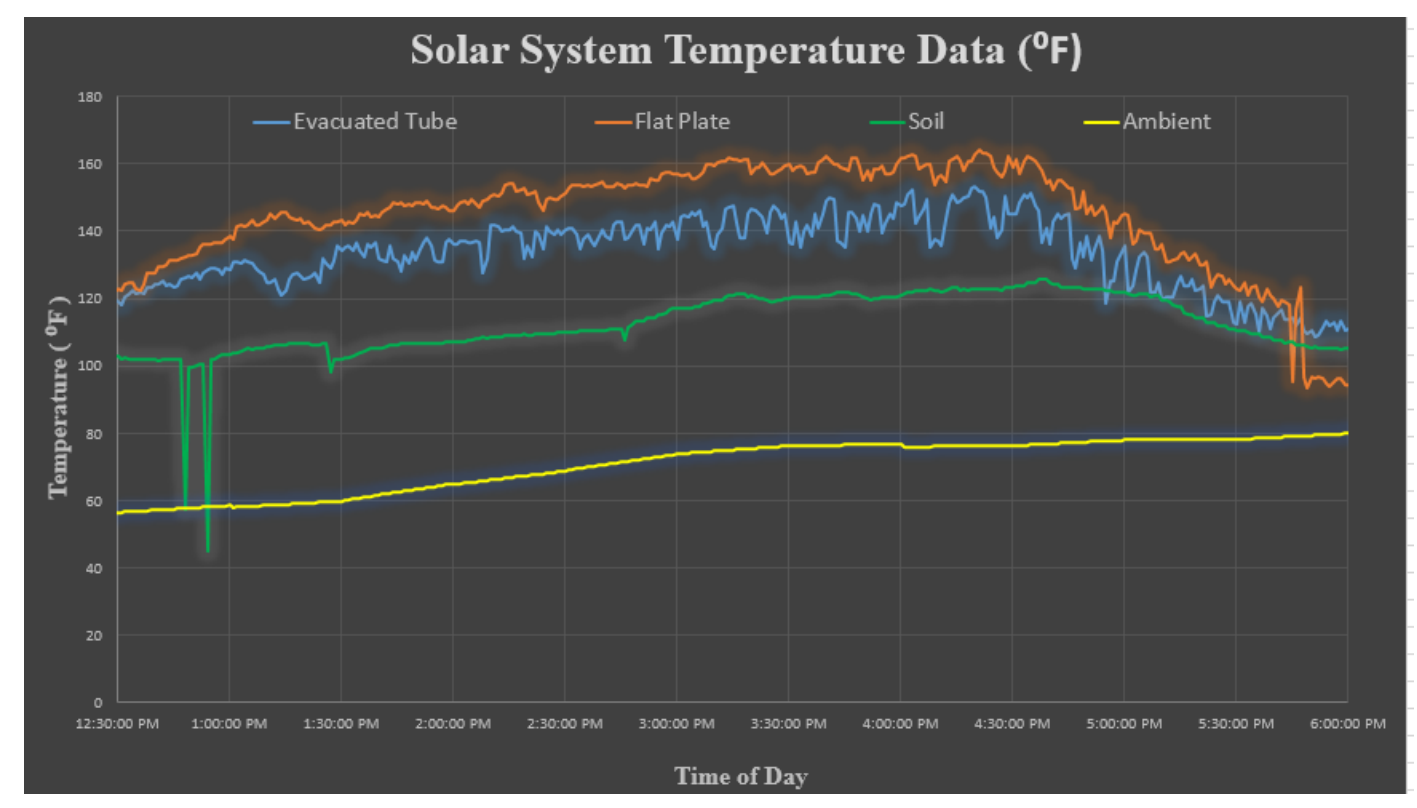

Figure 5: Solar temperature data

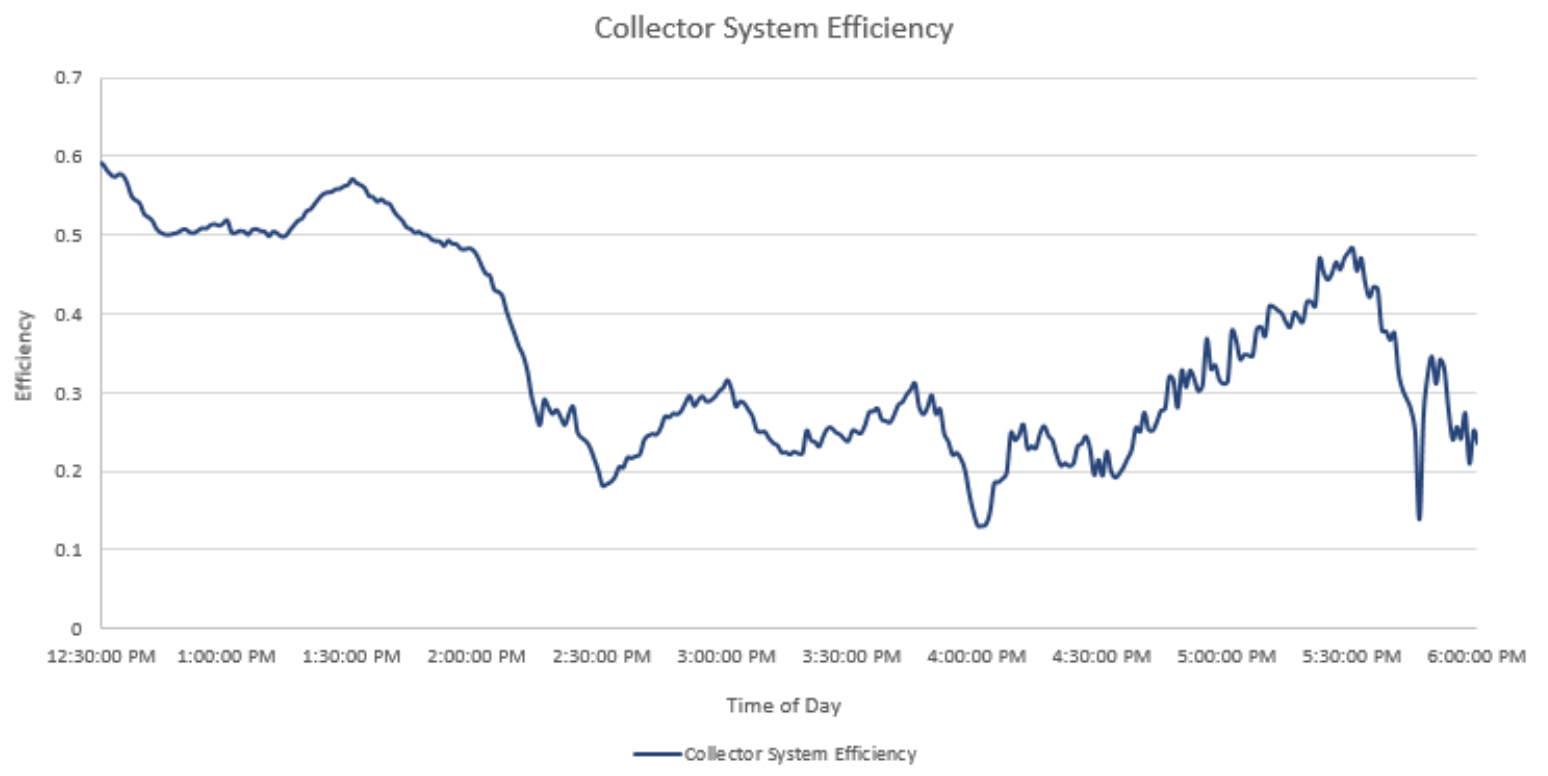

Figure 6: Collector system efficiency 


\section{Student Learning Experience for Green Energy Manufacturing}

For the past years, the focus has shifted towards incorporating renewable energy manufacturing topics in the senior design project course. In the first senior design project term, the students are assigned to the project topics related to renewable energy, power systems, or green energy manufacturing. These projects provide multi-disciplinary collaboration and valuable hands-on experience to the students. In addition to useful lessons on teamwork and project management, the project provides working demonstration of green energy manufacturing. During the first fall quarter of the course, each team is given with guidelines for the senior design project. The team demonstrates the senior design proposal to the entire class and then a written proposal summarizing the proposed activities is handed-in as one of requirements of the senior project design course. To enhance the hands-on experience, the senior design course has been restructured as a project-based course. Students are required to analyze, design, simulate, and build a completely functional system by the end-of-term project. The goal of the project was achieved to enhance student understanding of the fundamental concept of design-for-environment (dfE) and hands-on learning of green energy manufacturing. Students understood the design for the environment by improving and optimizing the environmental performance of products, impact on human health, associated energy, and material and process costs. Students commented that they enjoyed working in such green energy manufacturing project with hands-on laboratory experiments. The senior design project evaluations by the faculty and industrial advisory committee were very positive. This project received "outstanding" continuously every quarter in the Fall, Winter, and Spring of 20142015.

\section{Conclusions}

We believe that problem-based learning, as exemplified by a capstone Senior Design project such as this one, provides students with important knowledge about green design. In addition, such projects provide students with the essential project management and engineering skills required to bring complex projects from idea to completion. The project begins by defining a performance problem associated with applications and ends with a prototype for a green design solution. The problem drives the learning required to complete the project. Managing the project requires the students to demonstrate effective teamwork, clear communication and the ability to balance the social, economic and environmental impacts of the project. The goal of this project was to effectively heat a farming greenhouse using two types of solar heat exchangers. The team met with farmers to get a background on how they currently heat their greenhouses and what they would like to see in the future. In addition, as empathized, this alterative solution as compared to photovoltaic and resistive heating elements proves both more efficient and cost effective in the long term. This, in turn, will result in significantly decreased costs to farmers, greatly expanded ranges of profitable fruits and vegetable harvests, and a decrease in the environmental impact of greenhouse heating. Fundamentally, the design completed herein will also contribute vastly to the Drexel community at large as it can be used to demonstrate renewable energy systems to students for years to come. 


\section{Acknowledgement}

This work has been supported by the US Department of Education under the joint DHSIP Program with the University of Texas at El Paso, PR/Award No.: P031S120131. The authors wish to express sincere gratitude for their financial support.

\section{Bibliography}

1. Commercial Solar Water Heaters | Evacuated Tube Solar Thermal Collectors. (2014, January 1). Retrieved November 2, 2014, from http://www.solarpanelsplus.com/evacuated-tube-collectors/

2. Craig and Shannon Higginbotham (Personal Communication, November 7, 2014)

3. Mauk, M. (2014, October 17). Intellectual Property. Drexel Main Campus. Korman 104, Philadelphia, PA. Keynote address.

4. De Leon, N. (n.d.). Specific heat. Retrieved November 4, 2014, from http://www.iun.edu/ cpanhd/C101webnotes/matter-and-energy/specificheat.html

5. Edwards, T. (2014, October 24). Technology Commercialization. Drexel Main Campus. Korman 104, Philadelphia, PA. Keynote address.

6. Flat Panel Vs. Tube. (2010, March 1). Retrieved October 8, 2014, from..http://www.greenovation.ca/html/flat_pannel_vs tube.html

7. Holland Applied Technologies, "What Is Pump Head? How Is It Different than Pressure?" N.p., 07 Feb. 2014. Web. 1 May 2015.

8. Introduction to solar heat and hot water. (n.d.). Retrieved October 13, 2014, from http://www.yougen.co.uk/renewable-energy/Solar Thermal/

9. Mehalic, B. (2009, September 1). Flat-Plate \& Evacuated-Tube Solar Thermal Collectors. Retrieved October 17, 2014.

10. Said, Mohammed, Hess, Keith, and Heino, Zachary, “Automated Green Energy Solar Heating,” Senior Design Project, Drexel University, MET - 423 - 601, 2014 - 2015.

11. Solimon, A., Adams, J., \& Reidl, C. (2013). Hybrid Energy Integrator (p. 26). Philadelphia.

12. Satkowski, S. (2014, November 7). The Intersection of Product Design and the Law. Drexel Main Campus. Korman 103, Philadelphia, PA. Keynote address.

13. Williams, C. (2010, May 10). Which is Better: Solar Thermal Flat Plate or Evacuated Tube Collectors? Retrieved October 15, 2014.

14. Zambolin, E., \& Col, D. (n.d.). Experimental analysis of thermal performance of flat plate and evacuated tube solar collectors in stationary standard and daily conditions. Solar Energy, 1382-1396. 